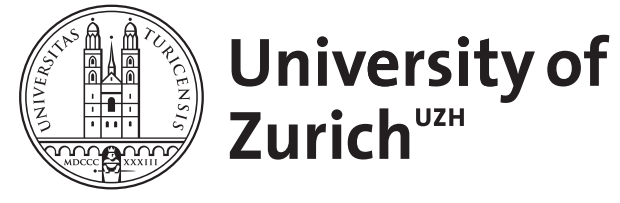
Archive

University of Zurich

University Library

Strickhofstrasse 39

CH-8057 Zurich

www.zora.uzh.ch

Year: 2018

\title{
Update on adjuvant melanoma therapy
}

Dimitriou, Florentia ; Braun, Ralph Peter ; Mangana, Joanna

DOI: https://doi.org/10.1097/CCO.0000000000000432

Posted at the Zurich Open Repository and Archive, University of Zurich

ZORA URL: https://doi.org/10.5167/uzh-144052

Journal Article

Published Version

Originally published at:

Dimitriou, Florentia; Braun, Ralph Peter; Mangana, Joanna (2018). Update on adjuvant melanoma therapy. Current Opinion in Oncology, 30(2):118-124.

DOI: https://doi.org/10.1097/CCO.0000000000000432 


\title{
Update on adjuvant melanoma therapy
}

\author{
Florentia Dimitriou $^{\mathrm{a}}$, Ralph Peter Braun ${ }^{\mathrm{a}, \mathrm{b}}$, and Joanna Mangana ${ }^{\mathrm{a}}$
}

\begin{abstract}
Purpose of review
We review the results from relevant clinical trials and discuss current strategies in the melanoma adjuvant setting.

\section{Recent findings}

The favorable therapeutic efficacy and the significant less toxicity of nivolumab compared with ipilimumab, fully substitutes today's approval of ipilimumab, regardless mutation status, whereas in BRAF-mutated patients, dabrafenib and trametinib seem to confirm their high efficacy also in adjuvant setting. The use of interferon is restricted to patients with ulcerated melanoma and countries with no access to the new drugs.
\end{abstract}

\begin{abstract}
Summary
Systemic adjuvant treatment after complete disease resection in high-risk melanoma patients aims to increase relapse-free survival (RFS) and overall survival (OS). According to the eighth edition of melanoma classification of American Joint Committee on Cancer (AJCC), the prognosis in stage III patients is heterogeneous and depends not only on $\mathrm{N}$ (nodal) but also on $\mathrm{T}$ (tumor thickness) category criteria. Recent data from randomized, phase-3 clinical trials analyzing the use of adjuvant anti-programmed death-1 and targeted therapies ultimately affect the standard of care and change the landscape of the adjuvant treatment.
\end{abstract}

\section{Keywords}

adjuvant, immunotherapy, melanoma, targeted therapy

\section{INTRODUCTION}

Checkpoint inhibitors as well as inhibitors of the mitogen-activated protein kinase pathway (MAPK) revolutionized the treatment era of advanced melanoma patients leading to their approval for metastatic disease [1-8,9"',10-16,17"',18,19',20]. Recently, spectacular outcomes were equivalently demonstrated in the adjuvant setting of patients with high risk for recurrence; however, choosing the right treatment at the right time remains an important clinical challenge $\left[21,22^{-"}, 23^{-"}, 24\right]$. Taking into account the high heterogeneity in stage III population and based on the American Joint Committee on Cancer (AJCC) staging system, the likelihood of recurrence or systemic disease correlates closely with tumor thickness and ulceration, microscopic versus macroscopic disease, the number of positive nodes as well as with presence of (micro)satellites or intransit metastasis $[25,26]$. Furthermore, the outcome of the sentinel lymph node biopsy (SLNB) is used for identification of high-risk groups, and decisions on frequency of follow-up, adjuvant therapy and enrollment into clinical trials [27-29].

This review will focus on the recent advances and the impact of immunotherapies and MAPK pathway-targeted therapies on clinical outcomes of high-risk melanoma patients. It will also examine the rationale behind current treatment choices in the real-life adjuvant setting.

\section{RADIOTHERAPY}

Radiotherapy provides an important variant in the treatment of patients with recurrent, in-transit or nodal metastatic melanoma requiring local control [30]. In the ANZMTG 01.02/TROC 02.01 phase 3, randomized controlled trial, 250 patients were enrolled to receive adjuvant radiotherapy of $48 \mathrm{~Gy}$ in 20 fractions or observation (OBS) [31]. The use of adjuvant radiotherapy after complete surgical resection significantly reduced the melanoma relapse in

\footnotetext{
${ }^{a}$ Department of Dermatology, University Hospital Zurich and ${ }^{b}$ Kein Division, University of Zurich, Zurich, Switzerland

Correspondence to Dr Joanna Mangana, MD, Department of Dermatology, University Hospital Zurich, Gloriastrasse 31, 8091 Zurich, Switzerland. Tel: +41 44255 1111;

e-mail: johanna.mangana@usz.ch
}

Curr Opin Oncol 2017, 29:000-000

DOI:10.1097/CCO.0000000000000432 


\section{KEY POINTS}

- The disease prognosis in stage III patients is heterogeneous and depends not only on $\mathrm{N}$ but also on $T$ category criteria, according to the eighth edition of melanoma classification of American Joint Committee on Cancer (AJCC).

- According to the recent clinical trials outcomes, current adjuvant treatment options are nivolumab for all patients regardless mutation status and dabrafenib/ trametinib for BRAF-mutated patients.

- The use of interferon is restricted to patients with ulcerated melanoma in countries with no access to the new drugs.

- Neoadjuvant therapy, upcoming adjuvant treatment combinations, for example, nivolumab with ipilimumab and identification of new biomarkers are expected to maximize the antitumor response.

the adjuvant radiotherapy group compared with OBS, but no differences regarding relapse-free survival (RFS) and overall survival (OS) were noted [31]. Long-term follow-up data support the primary findings. After a median follow-up of 73 months, 21\% relapses occurred in the adjuvant radiotherapy group compared with $36 \%$ in the OBS group [hazard ratio $0.52,95 \%$ confidence interval (CI) $0.31-0.88$, $P=0.023$ ] [32]. However, no significant difference regarding OS (hazard ratio 1.27, 95\% CI 0.89-1.79, $P=0.21$ ) and RFS (hazard ratio $0.89,95 \%$ CI $0.65-$ $1.22, P=0.51)$ was noted.

\section{IMIMNOTHERAPY}

Melanoma has been long considered an immunogenic cancer inducing significant antitumor responses and in some cases, spontaneous regression after immune-stimulating agent treatment [33-35]. As a result, multiple efforts in cytokine therapy, tumor vaccines, oncolytic viruses, adoptive immunotherapy and immune check point inhibition have been evaluated [33]. Some of these agents showed impressive activity not only in metastatic but also in the adjuvant setting and will be discussed here in further detail.

\section{Interferons}

Over the last 30 years, interferon (IFN) has been extensively investigated in patients with high-risk melanoma [36-44] (Table 1). Despite showing a rather modest activity - particularly whenever balanced against toxicity - it was the first agent worldwide approved in this setting. However, and partly because of substantial toxicity and treatment costs, there is a significant variation in different geographic locations regarding its use. High-dose IFN (HDI) for 12 months was until recently the

Table 1. Adjuvant trials determining adjuvant treatment in melanoma

\begin{tabular}{|c|c|c|c|c|c|c|}
\hline Study & Stage at study entry & Treatment arms (N) & $\begin{array}{l}\text { Median follow- } \\
\text { up (years) }\end{array}$ & RFS & os & Reference \\
\hline \multirow[t]{2}{*}{ ECOG E 1684} & $\begin{array}{l}\text { II and III (T4NOMO/ } \\
\text { TanyN+MO) }\end{array}$ & $\begin{array}{l}\text { High-dose IFN } \alpha 2 \text { a (HDI) } \\
\text { versus observation (287) }\end{array}$ & 6.9 & 0.61 & 0.67 & $\begin{array}{l}\text { Kirkwood } \\
\text { et al. [45] }\end{array}$ \\
\hline & & & 12.6 & 0.72 & 0.82 & \\
\hline \multirow[t]{2}{*}{ ECOG E1690 } & $\begin{array}{l}\text { II and III (T4NOMO/ } \\
\text { Tany } \mathrm{N}+\mathrm{MO})\end{array}$ & $\begin{array}{l}\text { HDI or LDI versus observation } \\
\quad(642)\end{array}$ & 4.3 & 0.78 & 1.0 & $\begin{array}{l}\text { Kirkwood } \\
\text { et al. [46] }\end{array}$ \\
\hline & & & 6.6 & 0.81 & 1.0 & \\
\hline \multirow[t]{2}{*}{ ECOG E1694 } & $\begin{array}{l}\text { II and III (T4NOMO/ } \\
\text { Tany N+MO) }\end{array}$ & $\begin{array}{l}\text { HDI versus GMK vaccine for } \\
96 \text { weeks (880) }\end{array}$ & 1.3 & 0.67 & 0.72 & $\begin{array}{l}\text { Kirkwood } \\
\text { et al. [47] }\end{array}$ \\
\hline & & & 2.1 & 0.75 & 0.76 & \\
\hline \multirow[t]{2}{*}{ EORTC 18991} & $\begin{array}{l}\text { III [Tany, N1 (occult)/ } \\
\text { N2 (bulky), MO] }\end{array}$ & $\begin{array}{l}\text { Pegylated IFN } \alpha 2 b \text { versus } \\
\text { observation }(1256)\end{array}$ & 3.8 & 0.82 & 0.98 & $\begin{array}{l}\text { Eggermont } \\
\text { et al. [37] }\end{array}$ \\
\hline & & & 7.6 & 0.87 & 0.96 & \\
\hline EORTC 18071 & $\begin{array}{l}\text { IIIA (N2a)/IIIB/IIIC } \\
\text { (except in transit) }\end{array}$ & $\begin{array}{l}\text { Ipilimumab } 10 \mathrm{mg} / \mathrm{kg} \text { versus } \\
\text { placebo (951) }\end{array}$ & 5.3 & 0.76 & 0.72 & $\begin{array}{l}\text { Eggermont } \\
\text { et al. [24] }\end{array}$ \\
\hline COMBI-AD & $\| I I A(>1 \mathrm{~mm}) / \mathrm{IIB} / \mathrm{IIIC}$ & $\begin{array}{l}\text { Dabrafenib } 150 \mathrm{mg} \text { b.i.d. with } \\
\text { trametinib } 2 \mathrm{mg} \text { q.d. versus } \\
\text { placebo (870) }\end{array}$ & 2.8 & 0.47 & 0.57 & $\begin{array}{l}\text { Long et al. } \\
\text { [23"-'] }\end{array}$ \\
\hline Checkmate-238 & IIIB/IIIC/IV & $\begin{array}{l}\text { Nivolumab } 3 \mathrm{mg} / \mathrm{kg} \text { versus } \\
\text { ipilimumab } 10 \mathrm{mg} / \mathrm{kg}(906)\end{array}$ & 1.5 & 0.65 & $?$ & $\begin{array}{c}\text { Weber et al. } \\
\text { [22"-] }\end{array}$ \\
\hline
\end{tabular}

OS, overall survival; RFS, relapse-free survival. 
standard of care in the United States and Australia, whereas intermediate and low doses are used in Europe and pegylated IFN is only approved in Switzerland for patients with micrometastasis and ulcerated primary tumors.

The E1684 clinical trial was the first trial demonstrating an improvement both in OS and RFS after a median follow-up time of 6.9 years. It investigated an induction phase of HDI intravenously administered at $20 \mathrm{MU} / \mathrm{m}^{2}$ for five consecutive weeks followed by subcutaneous administration of $10 \mathrm{MU} / \mathrm{m}^{2}$ of IFN three times a week for 48 weeks versus placebo. 5-year RFS was 37\% (95\% CI 30-46\%) compared with $26 \%$ (95\% CI 19-34\%), and 5-year OS was $46 \%$ (95\% CI 39-55\%) versus 37\% (95\% CI 30$46 \%)$ in favor of HDI [45]. HDI for 1 year and lowdose IFN for a treatment period of 2 years were compared with postoperative OBS in the E1690 trial [46]. HDI significantly improved RFS $(P=0.03)$ compared with OBS after a median follow-up of 4.3 years, but no differences were seen in OS. E1694 trial followed and tested HDI for 1 year versus the ganglioside vaccine GMK (Progenics pharmaceuticals) for 96 weeks [47]. Herein, OS and RFS were significantly improved in favor of HDI (hazard ratio 0.72 and 0.67 , respectively). Subsequently, a number of trials trying to identify the optimal dose, schedule and duration of adjuvant IFN have followed $[38,41,48-52]$. In a pooled meta-analysis of nearly 2000 patients including E1684, E1690 and E1694 trials, HDI maintained substantial RFS but not OS benefit $(P=0.006)$ [39]. Other meta-analyses demonstrated a modest impact in OS (approximately 3\%, 95\% CI 1-5\%) with ulceration being the most predictive factor for response to IFN $[37,40,42,48,53-55]$.

\section{CTLA-4 inhibition}

Ipilimumab, a fully human monoclonal antibody that blocks CTLA-4, was approved by the Federal Drug Administration (FDA) for treatment of patients with advanced melanoma in 2011 [11]. The efficacy of ipilimumab in the adjuvant setting has been evaluated in two randomized phase III clinical trials either compared with placebo (EORTC 18071) [21] or HDI (ECOG 1609, NTC01274338).

The EORTC 18071 clinical trial enrolled 951 melanoma patients with stage IIIA (N2a), IIIB and IIIC disease after complete resection and high risk of recurrence [21]. Patients were 1:1 randomly assigned to receive ipilimumab at a dose of $10 \mathrm{mg} /$ $\mathrm{kg}$ or placebo every 3 weeks for four doses, following every 3 months for up to 3 years. The study met its primary endpoint of RFS in 2.7 years. Ipilimumab was shown to significantly improve RFS at 26.1 months (95\% CI 19.3-39.3) compared with 17.1 months (95\% CI 13.4-21.6) in the placebo group (hazard ratio $0.75,95 \%$ CI $0.64-0.90, P=0.0013$ ) [21]. Recent data of 5.3 years' median follow-up confirm the RFS and OS benefit (RFS 40.8 versus $30.3 \%$, hazard ratio $0.76,95 \%$ CI $0.64-0.89$, OS 65.4 versus $54.4 \%$, hazard ratio $0.72,95 \%$ CI $0.58-0.88$ ) [24] (Table 1). Benefit was consistent in all subgroups, though patients with ulcerated primary lesions seem to benefit the most.

As current dose of ipilimumab $10 \mathrm{mg} / \mathrm{kg}$ in the adjuvant setting is significantly higher than the dose approved for metastatic melanoma ( $3 \mathrm{mg} / \mathrm{kg})$, questions have been raised regarding the dose relation to higher toxicity [56]. The ECOG-E1609 clinical trial compares ipilimumab 10 or $3 \mathrm{mg} / \mathrm{kg}$ versus high-dose recombinant IFN $\alpha$ in resected stages IIIB and IIIC (including in-transit metastases) and stage IV melanoma with primary endpoints, the OS and progression-free survival (PFS). An unplanned RFS analysis was recently presented, showing no substantial difference in PFS for patients treated with $3 \mathrm{mg} / \mathrm{kg}$ compared with $10 \mathrm{mg} / \mathrm{kg}$ [57]. Updated results of this trial are expected in May 2018.

\section{PD1 inhibition}

Anti-programmed death-1 (anti-PD1) blockade has demonstrated significant benefits in RFS and OS in metastatic melanoma with superior efficacy to ipilimumab [8,16,19"]. These encouraging data along with a favorable toxicity profile prompted their application in the adjuvant setting.

The phase 3 clinical trial comparing ipilimumab $10 \mathrm{mg} / \mathrm{kg}$ to nivolumab $3 \mathrm{mg} / \mathrm{kg}$ in fully resected stage IIIB/IIIC-IV melanoma patients reformed the adjuvant treatment era (Checkmate-238) [22"']. Nine hundred and six patients were $1: 1$ randomized to nivolumab $3 \mathrm{mg} / \mathrm{kg}$ every 2 weeks versus ipilimumab $10 \mathrm{mg} / \mathrm{kg}$ every 3 weeks for 4 doses and then every 12 weeks for 1 year till disease recurrence or unacceptable toxicity. After 18 months of follow-up, nivolumab showed a significant superiority over adjuvant ipilimumab treatment, with RFS of 70.5\% (95\% CI 66.1-75.4) versus 60.8\% (95\% CI 56.0-65.2), hazard ratio $0.65 ; P<0.001$ [22"']. Adjuvant treatment with nivolumab seems to have higher benefit in patients with stage IIIB/IIIC and PD-L1 expression more than $5 \%$, regardless of BRAF status.

Other ongoing clinical trials investigating the application of anti-PD1 agents in the adjuvant setting are the EORTC 1325 (KEYNOTE-054) comparing pembrolizumab $200 \mathrm{mg}$ flat dose versus placebo (NCT02362594) and the SWOG S1404 protocol comparing pembrolizumab $200 \mathrm{mg}$ flat dose to HDI [58]. 
As combination of CTLA-4 with PD-1 blockade has been proved to augment the immune response compared with each agent alone in metastatic melanoma [17"'], the Checkmate-915 clinical trial is currently underway, comparing adjuvant nivolumab combined with ipilimumab versus nivolumab monotherapy (NCT03068455). This phase-3 study enrolls patients after complete resection of stage IIIB/IIIC/IIID or stage IV melanoma, according to the eighth AJCC edition.

\section{TARGETED THERAPY}

In addition to immunotherapy, inhibition of the MAPK pathway resulted in outstanding activity in the adjuvant setting as recently presented in the European Association of Medical Oncology Meeting (ESMO), this year in Madrid. The Combi-AD randomized double-blind phase III clinical trial enrolled 870 patients with completed resected stage III melanoma harboring the BRAF V600E or V600K mutation to receive either dabrafenib $150 \mathrm{mg}$ twice daily with trametinib at a dose of $2 \mathrm{mg}$ once daily or two matched placebo. Patients were treated for a maximum of 1 year in the absence of disease progression or until unacceptable toxicity or study withdrawal. Among the study population, 18\% (154 patients) had a stage IIIA disease with a micrometastasis in SLNB of more than $1 \mathrm{~mm}$. At a median of 2.8 years follow-up, investigation-assessed RFS was significantly longer in the combination group resulting in a 53\% lower risk for death or relapse (hazard ratio $0.47 ; 95 \%$ CI $0.39-0.58 ; P<0.0001$ ). Estimated rates for RFS at the first, second and third year were 88,67 and $58 \%$ for the combination group in comparison with 56, 44 and 39\% for the placebo group, respectively. Combination treatment resulted in higher rates of OS and distant-metastasis-free survival (DMFS) with a 3-year OS of $86 \%$ in the combination group versus $77 \%$ in the placebo group and a 3-year DMFS of 71 versus 57\%, respectively (Table 1). Clinical benefit was consistent across all subgroups of patients regardless of ulceration of primary tumor or lymph-node involvement.

The randomized BRIM8 trial of adjuvant vemurafenib versus placebo, however, in patients with resected BRAF-mutant melanoma and high risk of recurrence did not manage to improve the primary endpoint of RFS but seems to be effective with manageable safety profile in patients with stage IIC-IIIB melanoma [59].

\section{TOXICITY}

The toxicity profile in the adjuvant setting is confirming the existing experience in advanced melanoma. Adverse events occur less frequent with anti-PD1 antibodies than with ipilimumab with a comparable toxicity profile, including diarrhea, colitis, endocrinologic adverse events (hypophysitis, hyperthyroidism and hypothyroidism, adrenal dysfunction), vitiligo, pruritus, rash and fatigue $[60,61]$. Patients enrolled in the EORTC 18071 trial developed a high rate of grade 3-5 immune-related adverse events (irAEs; 43 compared with $2 \%$ in placebo group), including five treatment-related deaths (colitis, $n=3$; myocarditis, $n=1$; multiorgan failure with Guillan-Barre syndrome, $n=1$ ) [21]. Comparing the safety profile of the Checkmate238 trial, nivolumab showed significantly less toxicity. Grade 3-4 adverse events occurred in $14.4 \%$ of the patients in the nivolumab group and in $45.9 \%$ in the ipilimumab group and led to discontinuation in 3.5 and $30 \%$, respectively [22"']. These irAEs are, however, manageable through early application of high-dose corticosteroids or other immune modulatory agents.

Albeit, immunotherapy and targeted therapy have different toxicity profiles. Taking a closer look into the Combi-AD trial, the most common adverse events appear to be pyrexia, fatigue and nausea, whereas grade 3-4 toxicities occurred in $41 \%$ in the combination group versus $14 \%$ in the placebo group [23"']. The number of treatment discontinuations seems to be higher compared with stage IV melanoma (26 versus 16\%, respectively, though no new adverse events were observed.

High-dose interferon- $\alpha 2 b$ is associated with high toxicity, such as chronic fatigue (96\%), myelosuppression (92\%), elevated liver enzyme levels [63\% increased aspartate aminotransferase (AST)] and neurologic symptoms (40\%), which affect the majority of patients and can lead to premature treatment discontinuation [62].

\section{INTEGRATING CURRENT ADJUVANT TREATMENT INTO CLINICAL PRACTICE}

Putting this data together, there is yet no consensus available for treatment selection in melanoma patients with high risk for recurrence. As neither nivolumab nor dabrafenib and trametinib combination therapy have been so far approved by the regulatory authorities for this indication, the suggestions that follows are hinged on the results of the available studies. However, and considering that the surgical procedures and the staging system have changed since the initiation of these trials, there is a certain gap of knowledge affecting the adjuvant field. The recommendations that follows have been adapted to the new AJCC, eighth edition. 


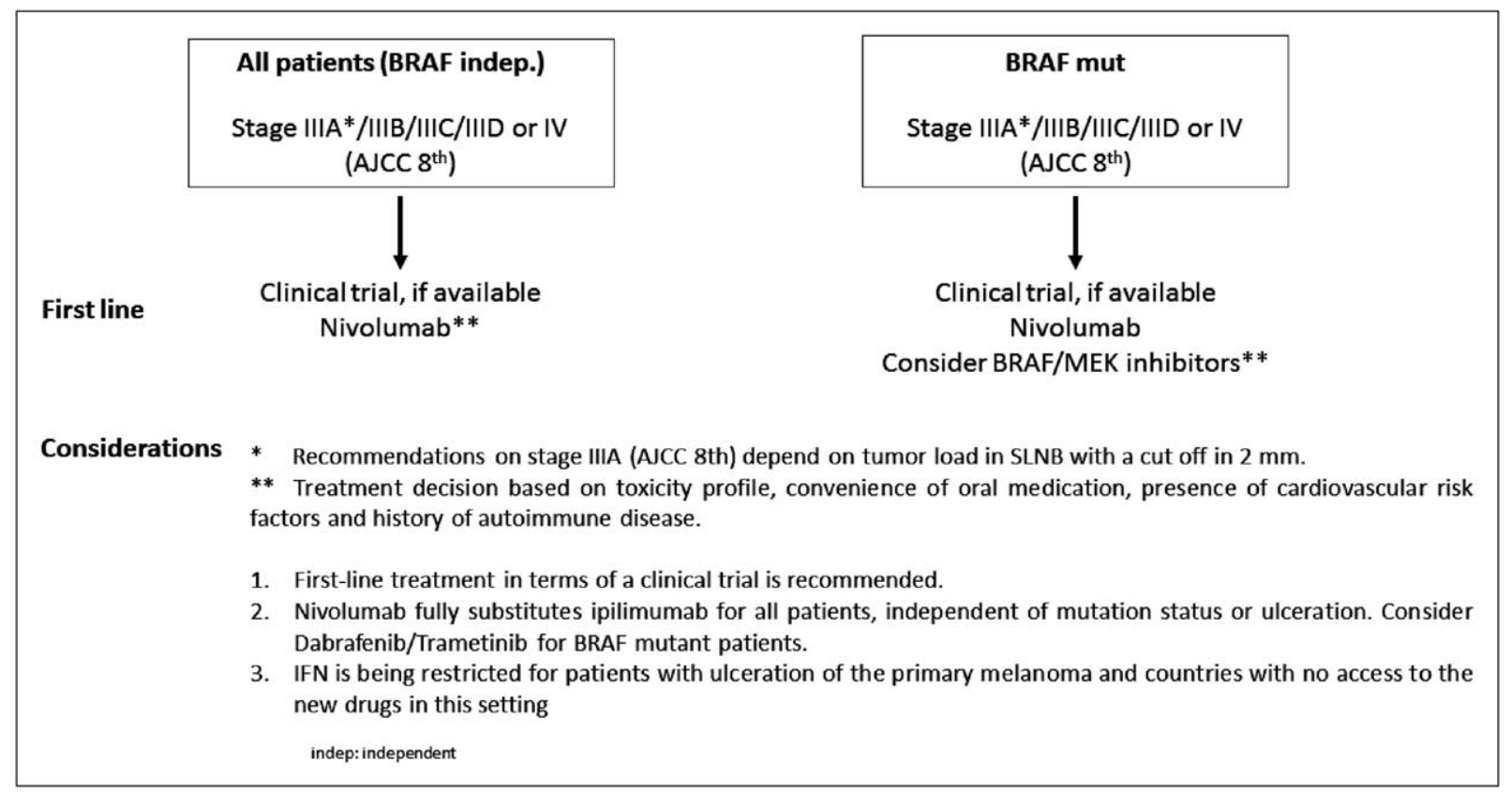

FIGURE 1. First-line choice recommendation for adjuvant treatment.

Taking into account, the modest impact in OS and the substantial toxicity related to IFN and based on the impressive new data, we believe that the role of IFN will be restricted for patients with ulceration of the primary melanoma for countries with no access to the new drugs in this setting. For the same reasons and owing to the superior efficacy of nivolumab compared with ipilimumab, the future of the latter as monotherapy seems scanty. Whether combination of low-dose ipilimumab with nivolumab would have a place in the adjuvant setting remains an open question, and BMS-219 will definitely give new insights with early results expected in the following 2-3 years.

In addition to enrollment into clinical trials, which is the first-line choice for melanoma patients with high-risk of recurrence, nivolumab would be the appropriate adjuvant therapy for all patients independent of mutation status or ulceration (Fig. 1). For V600 mutant patients, combination dabrafenib and trametinib is a considerable alternative (Fig. 1). Whenever comparing the available evidence, the data of Combi-AD are more mature, although consistent to Checkmate 238 (Table 1). Decision should be based on individual factors such as toxicity profile, convenience of oral medication, or presence of cardiovascular risk factors and history of autoimmune disease.

One important question arising is whether all stage III or M1a patients should receive adjuvant therapy. Both DECOG and MSLT 2 trials showed no differences in clinical outcome after complete lymphadenectomy (CLND) $[63,64]$. Several countries do not currently recommend CLND whenever micrometastasis of less than $1 \mathrm{~mm}$ in SLNB (clinically occult disease) is present; instead patients undergo more intensive surveillance. We favor adjuvant treatment in high-risk patients from stage IIIB/ IIIC, whereas the recommendations on stage IIIA (T1a/b-T2a N1a or N2a) depend on tumor load in SLNB with a cut off of $2 \mathrm{~mm}$ (Fig. 1). In general, and according to the AJCC eighth edition, IIIA patients have a favorable prognosis compared with IIIB and IIIC patients with a 10-year survival of 88 versus 77 and $60 \%$, respectively. Five-year survival for patients with metastasis of a maximum dimension of $2-$ $4 \mathrm{~mm}$ in SLNB was similar to that of $1-2 \mathrm{~mm}$ (86 versus $89 \%$, respectively). In IIIB-IIIC stages with clinically occult N disease only (pT2b-4b N1a/N2a) the approach is similar to clinically detectable disease (pN1b-N3c), where adjuvant treatment is strongly recommended, as ulceration and tumor thickness are both strong predictors of impaired outcome in patients with N-positive disease.

\section{CONCLUSION}

Taking into consideration the limited maturity of the data available, a definite suggestion of the firstline adjuvant treatment remains onerous. Nivolumab seems to fully substitute ipilimumab with a statistically significant improvement in RFS and less 
toxicities. Combination dabrafenib and trametinib presents an important alternative in BRAF mutant patients (Fig. 1). Additionally, the use of both agents in neo-adjuvant setting offers very attractive choices for future clinical trial design.

All in all, the ongoing evaluation of antitumor antigens, the identification of new biomarkers and the understanding of treatment resistance mechanisms is expected to guide the selection of treatment and maximize the antitumor response.

\section{Acknowledgements}

None.

\section{Financial support and sponsorship}

None.

\section{Conflicts of interest}

J.M. has temporary advisory relationships and receives travel support from Bristol-Myers Squibb (BMS), Merck Sharp \& Dhome (MSD) and Merck/Pfizer.

\section{REFERENCES AND RECOMMENDED READING}

Papers of particular interest, published within the annual period of review, have been highlighted as:

- of special interest

I. of outstanding interest

1. Chapman $P B$, Hauschild $A$, Robert $C$, et al. Improved survival with vemurafenib in melanoma with BRAF V600E mutation. N Engl J Med 2011; 364:2507-2516.

2. Long GV, Stroyakovskiy D, Gogas $\mathrm{H}$, et al. Combined BRAF and MEK inhibition versus BRAF inhibition alone in melanoma. N Engl J Med 2014; $371: 1877-1888$.

3. Postow MA, Chesney J, Pavlick AC, et al. Nivolumab and ipilimumab versus ipilimumab in untreated melanoma. N Engl J Med 2015; 372:2006-2017.

4. Robert C, Karaszewska B, Schachter J, et al. Improved overall survival in melanoma with combined dabrafenib and trametinib. N Engl J Med 2015; 372:30-39.

5. Robert C, Long GV, Brady B, et al. Nivolumab in previously untreated melanoma without BRAF mutation. N Engl J Med 2015; 372:320-330.

6. Robert $\mathrm{C}$, Thomas $\mathrm{L}$, Bondarenko I, et al. Ipilimumab plus dacarbazine for previously untreated metastatic melanoma. N Engl J Med 2011; 364: $2517-2526$.

7. Larkin J, Ascierto PA, Dreno B, et al. Combined vemurafenib and cobimetinib in BRAF-mutated melanoma. N Engl J Med 2014; 371:1867-1876.

8. Robert C, Schachter J, Long GV, et al. Pembrolizumab versus ipilimumab in advanced melanoma. N Engl J Med 2015; 372:2521-2532.

9. Schadendorf D, Long GV, Stroiakovski D, et al. Three-year pooled analysis of

- factors associated with clinical outcomes across dabrafenib and trametinib combination therapy phase 3 randomised trials. Eur J Cancer 201 7; 82:45-55.

This article demonstrated that durable responses under kinase inhibitors are possible. Baseline LDH level and number of organ sites are strongly associated with and/or predictive of PFS and OS.

10. Ascierto PA, McArthur GA, Dreno B, et al. Cobimetinib combined with vemurafenib in advanced BRAF(V600)-mutant melanoma (coBRIM): updated efficacy results from a randomised, double-blind, phase 3 trial. Lancet Oncol 2016; 17:1248-1260.

11. Hodi FS, O'Day SJ, McDermott DF, et al. Improved survival with ipilimumab in patients with metastatic melanoma. N Engl J Med 2010; 363:711-723.

12. Long GV, Stroyakovskiy $D$, Gogas $\mathrm{H}$, et al. Dabrafenib and trametinib versus dabrafenib and placebo for Val600 BRAF-mutant melanoma: a multicentre, double-blind, phase 3 randomised controlled trial. Lancet 2015; 386: 444-451.

13. McArthur GA, Chapman PB, Robert $C$, et al. Safety and efficacy of vemurafenib in BRAF(V600E) and BRAF(V600K) mutation-positive melanoma (BRIM-3): extended follow-up of a phase 3, randomised, open-label study. Lancet Oncol 2014; 15:323-332
14. Ugurel S, Rohmel J, Ascierto PA, et al. Survival of patients with advanced metastatic melanoma: the impact of novel therapies-update 2017. Eur J Cancer 2017; 83:247-257.

15. Flaherty KT, Robert $C$, Hersey $P$, et al. Improved survival with MEK inhibition in BRAF-mutated melanoma. N Engl J Med 2012; 367:107-114.

16. Schachter J, Ribas A, Long GV, et al. Pembrolizumab versus ipilimumab for advanced melanoma: final overall survival results of a multicentre, randomised, open-label phase 3 study (KEYNOTE-006). Lancet 2017; 390:1853-1862.

17. Wolchok JD, Chiarion-Sileni V, Gonzalez R, et al. Overall survival with

1. combined nivolumab and ipilimumab in advanced melanoma. N Engl J Med $2017 ; 377: 1345-1356$.

This article demonstrates the first overall survival data under combination immunotherapy.

18. Ribas A, Puzanov I, Dummer R, et al. Pembrolizumab versus investigatorchoice chemotherapy for ipilimumab-refractory melanoma (KEYNOTE-002): a randomised, controlled, phase 2 trial. Lancet Oncol 2015; 16:908-918.

19. Weber JS, D'Angelo SP, Minor D, et al. Nivolumab versus chemotherapy in

- patients with advanced melanoma who progressed after anti-CTLA-4 treatment (CheckMate 037): a randomised, controlled, open-label, phase 3 trial. Lancet Oncol 2015; 16:375-384.

This phase III study showed superiority of nivolumab ( $3 \mathrm{mg} \mathrm{Q} 2 \mathrm{~W}$ ) versus chemotherapy in advanced melanoma patients.

20. Hodi FS, Chesney J, Pavlick AC, et al. Combined nivolumab and ipilimumab versus ipilimumab alone in patients with advanced melanoma: 2 -year overall survival outcomes in a multicentre, randomised, controlled, phase 2 trial. Lancet Oncol 2016; 17:1558-1568.

21. Eggermont $A M$, Chiarion-Sileni V, Grob JJ, et al. Adjuvant ipilimumab versus placebo after complete resection of high-risk stage III melanoma (EORTC 18071): a randomised, double-blind, phase 3 trial. Lancet Oncol 2015; 16:522-530.

22. Weber J, Mandala $M$, Del Vecchio $M$, et al. Adjuvant nivolumab versus

1. ipilimumab in resected stage III or IV melanoma. N Engl J Med 2017; $377: 1824-1835$.

This study showed that nivolumab resulted in a 35\% lower risk for relapse or death in high-risk melanoma patients compared with ipilimumab alone.

23. Long GV, Hauschild A, Santinami M, et al. Adjuvant dabrafenib plus trametinib -. in stage III BRAF-mutated melanoma. N Engl J Med 2017; 377:1813-1823. Combination treatment with dabrafenib and trametinib resulted in in a $53 \%$ lower risk for death or relapse compared with placebo. Estimated rates for RFS at the first, second and third year were 88,67 and $58 \%$ for the combination group in comparison with 56,44 and $39 \%$ for the placebo group, respectively.

24. Eggermont AM, Chiarion-Sileni V, Grob JJ, et al. Prolonged survival in stage III melanoma with ipilimumab adjuvant therapy. N Engl J Med 2016; 375: $1845-1855$.

25. Charles $\mathrm{M}$, Balch. Jeffrey $\mathrm{E}$, et al. Multivariate analysis of prognostic factors among 2,313 patients with stage III melanoma: comparison of nodal micrometastases versus macrometastases. J Clin Oncol 2010; 28:2452-2459.

26. Gershenwald JE, Scolyer RA, Hess KR, et al. Melanoma staging: evidencebased changes in the American Joint Committee on Cancer eighth edition cancer staging manual. CA Cancer J Clin 2017; 67:472-492.

27. van Akkooi $A C$, Nowecki Zl, Voit $C$, et al. Sentinel node tumor burden according to the Rotterdam criteria is the most important prognostic factor for survival in melanoma patients: a multicenter study in 388 patients with positive sentinel nodes. Ann Surg 2008; 248:949-955.

28. van der Ploeg AP, van Akkooi $A C$, Rutkowski $P$, et al. Prognosis in patients with sentinel node-positive melanoma is accurately defined by the combined Rotterdam tumor load and Dewar topography criteria. J Clin Oncol 2011; 29:2206-2214

29. van der Ploeg AP, van Akkooi AC, Haydu LE, et al. The prognostic significance of sentinel node tumour burden in melanoma patients: an international, multicenter study of 1539 sentinel node-positive melanoma patients. Eur J Cancer 2014; 50:111-120.

30. Bentzen SM, Overgaard J, Thames HD, et al. Clinical radiobiology of malignant melanoma. Radiother Oncol 1989; 16:169-182.

31. Burmeister $\mathrm{BH}$, Henderson MA, Ainslie J, et al. Adjuvant radiotherapy versus observation alone for patients at risk of lymph-node field relapse after therapeutic lymphadenectomy for melanoma: a randomised trial. Lancet Oncol 2012; 13:589-597.

32. Henderson MA, Burmeister $\mathrm{BH}$, Ainslie J, et al. Adjuvant lymph-node field radiotherapy versus observation only in patients with melanoma at high risk of further lymph-node field relapse after lymphadenectomy (ANZMTG 01.02/ TROG 02.01): 6-year follow-up of a phase 3, randomised controlled trial. Lancet Oncol 2015; 16:1049-1060.

33. Sznol M. Betting on immunotherapy for melanoma. Curr Oncol Rep 2009; 11:397-404.

34. Komenaka I, Hoerig H, Kaufman HL. Immunotherapy for melanoma. Clin Dermatol 2004; 22:251-265.

35. Gogas $\mathrm{H}$, loannovich J, Dafni U, et al. Prognostic significance of autoimmunity during treatment of melanoma with interferon. N Engl J Med 2006; 354:709-718.

36. Eggermont AM, Suciu S, Santinami M, et al. Adjuvant therapy with pegylated interferon alfa- $2 \mathrm{~b}$ versus observation alone in resected stage III melanoma: final results of EORTC 18991, a randomised phase III trial. Lancet 2008; $372: 117-126$ 
37. Eggermont AM, Suciu S, Testori A, et al. Long-term results of the randomized phase III trial EORTC 18991 of adjuvant therapy with pegylated interferon alfa-2b versus observation in resected stage III melanoma. J Clin Oncol 2012; 30:3810-3818.

38. Grob JJ, Dreno B, de la Salmoniere $P$, et al. Randomised trial of interferon alpha-2a as adjuvant therapy in resected primary melanoma thicker than $1.5 \mathrm{~mm}$ without clinically detectable node metastases. French Cooperative Group on Melanoma. Lancet 1998; 351:1905-1910.

39. Kirkwood JM, Manola J, Ibrahim J, et al. A pooled analysis of eastern cooperative oncology group and intergroup trials of adjuvant high-dose interferon for melanoma. Clin Cancer Res 2004; 10:1670-1677.

40. Wheatley $\mathrm{K}$, Ives $\mathrm{N}$, Hancock $\mathrm{B}$, et al. Does adjuvant interferon-alpha for highrisk melanoma provide a worthwhile benefit? A meta-analysis of the randomised trials. Cancer Treat Rev 2003; 29:241-252.

41. Hancock BW, Wheatley $\mathrm{K}$, Harris $\mathrm{S}$, et al. Adjuvant interferon in high-risk melanoma: the AIM HIGH Study-United Kingdom Coordinating Committee on Cancer Research randomized study of adjuvant low-dose extended-duration interferon Alfa-2a in high-risk resected malignant melanoma. J Clin Oncol 2004; 22:53-61.

42. Mocellin S, Pasquali S, Rossi CR, Nitti D. Interferon alpha adjuvant therapy in patients with high-risk melanoma: a systematic review and meta-analysis. J Natl Cancer Inst 2010; 102:493-501.

43. Pectasides D, Dafni U, Bafaloukos D, et al. Randomized phase III study of 1 month versus 1 year of adjuvant high-dose interferon alfa- $2 b$ in patients with resected high-risk melanoma. J Clin Oncol 2009; 27:939-944.

44. Agarwala SS, Lee SJ, Yip W, et al. Phase III randomized study of 4 weeks of high-dose interferon- $\alpha-2 b$ in stage T2bNO, T3a-bNO, T4a-bNO, and T14N1a-2a (microscopic) melanoma: a trial of the Eastern Cooperative Oncology Group-American College of Radiology Imaging Network Cancer Research Group (E1697). J Clin Oncol 2017; 35:885-892.

45. Kirkwood JM, Strawderman MH, Ernstoff MS, et al. Interferon alfa-2b adjuvant therapy of high-risk resected cutaneous melanoma: the Eastern Cooperative Oncology Group Trial EST 1684. J Clin Oncol 1996; 14:7-17.

46. Kirkwood JM, Ibrahim JG, Sondak VK, et al. High- and low-dose interferon alfa$2 \mathrm{~b}$ in high-risk melanoma: first analysis of intergroup trial E1690/S9111/ C9190. J Clin Oncol 2000; 18:2444-2458.

47. Kirkwood JM, Ibrahim JG, Sosman JA, et al. High-dose interferon alfa-2b significantly prolongs relapse-free and overall survival compared with the GM2-KLH/ QS-21 vaccine in patients with resected stage IIB-III melanoma: results of intergroup trial E1694/S9512/C509801. J Clin Oncol 2001; 19:2370-2380.

48. Eggermont AM, Suciu S, MacKie R, et al. Postsurgery adjuvant therapy with intermediate doses of interferon alfa $2 \mathrm{~b}$ versus observation in patients with stage Ilb/III melanoma (EORTC 18952): randomised controlled trial. Lancet 2005; 366:1189-1196.

49. Garbe C, Radny P, Linse R, et al. Adjuvant low-dose interferon \{alpha\}2a with or without dacarbazine compared with surgery alone: a prospective-randomized phase III DeCOG trial in melanoma patients with regional lymph node metastasis. Ann Oncol 2008; 19:1195-1201.

50. Pehamberger $\mathrm{H}$, Soyer HP, Steiner A, et al. Adjuvant interferon alfa-2a treatment in resected primary stage II cutaneous melanoma. Austrian Malignant Melanoma Cooperative Group. J Clin Oncol 1998; 16:1425-1429.
51. Cascinelli N, Belli F, MacKie RM, et al. Effect of long-term adjuvant therapy with interferon alpha-2a in patients with regional node metastases from cutaneous melanoma: a randomised trial. Lancet 2001; 358: 866-869.

52. Cameron DA, Cornbleet MC, Mackie RM, et al. Adjuvant interferon alpha $2 b$ in high risk melanoma - the Scottish study. Br J Cancer 2001; 84: $1146-1149$

53. Suciu S, Ives N, Eggermont AM, et al. Predictive importance of ulceration on the efficacy of adjuvant interferon-a (IFN): an individual patient data (IPD) meta-analysis of 15 randomized trials in more than 7,500 melanoma patients (pts). J Clin Oncol 2014; 32:. (abstract 9067).

54. Eggermont $A M$, Suciu $S$, Rutkowski $P$, et al. Long term follow up of the EORTC 18952 trial of adjuvant therapy in resected stage IIB-III cutaneous melanoma patients comparing intermediate doses of interferon-alpha- $2 b$ (IFN) with observation: ulceration of primary is key determinant for IFNsensitivity. Eur J Cancer 2016; 55:111-121.

55. Eggermont AM, Suciu S, Testori A, et al. Ulceration and stage are predictive of interferon efficacy in melanoma: results of the phase III adjuvant trials EORTC 18952 and EORTC 18991. Eur J Cancer 2012; 48:218-225.

56. Ascierto PA, Del Vecchio M, Robert $C$, et al. Ipilimumab $10 \mathrm{mg} / \mathrm{kg}$ versus ipilimumab $3 \mathrm{mg} / \mathrm{kg}$ in patients with unresectable or metastatic melanoma: a randomised, double-blind, multicentre, phase 3 trial. Lancet Oncol 2017; 18:611-622.

57. Tarhini AA, Lee SJ, Hodi FS, et al. A phase III randomized study of adjuvant ipilimumab ( 3 or $10 \mathrm{mg} / \mathrm{kg}$ ) versus high-dose interferon alfa- $2 \mathrm{~b}$ for resected high-risk melanoma (U.S. Intergroup E1609): preliminary safety and efficacy of the ipilimumab arms. J Clin Oncol 2017; 35(15 suppl):9500.

58. Grossmann KF, Othus M, Tarhini AA, et al. SWOG S1404: A phase III randomized trial comparing standard of care adjuvant therapy to pembrolizumab in patients with high risk resected melanoma. J Clin Oncol 2016; 34(15 suppl); e21032.

59. Lewis $\mathrm{K}$, Maio $M$, Demidov $L$, et al. BRIM8: a randomized, double-blind, placebo-controlled study of adjuvant vemurafenib in patients (pts) with completely resected, BRAFV600+ melanoma. Ann Oncol 2017; 28(Suppl 5):v605-v649.

60. Hofmann L, Forschner A, Loquai C, et al. Cutaneous, gastrointestinal, hepatic, endocrine, and renal side-effects of anti-PD-1 therapy. Eur J Cancer 2016; 60:190-209.

61. Zimmer L, Goldinger SM, Hofmann L, et al. Neurological, respiratory, musculoskeletal, cardiac and ocular side-effects of anti-PD-1 therapy. Eur J Cancer 2016; 60:210-225.

62. Kirkwood JM, Bender $\mathrm{C}$, Agarwala $\mathrm{S}$, et al. Mechanisms and management of toxicities associated with high-dose interferon alfa-2b therapy. J Clin Oncol 2002; 20:3703-3718.

63. Leiter U, Stadler R, Mauch $\mathrm{C}$, et al. Complete lymph node dissection versus no dissection in patients with sentinel lymph node biopsy positive melanoma (DeCOG-SLT): a multicentre, randomised, phase 3 trial. Lancet Oncol 2016; 17:757-767.

64. Faries MB, Thompson JF, Cochran AJ, et al. Completion dissection or observation for sentinel-node metastasis in melanoma. $\mathrm{N}$ Engl J Med 2017; 376:2211-2222. 